\title{
Kotler, Philip y Caslione, John A. (2009): La ciencia del caos. El Managment y el Marketing en la era de las turbulencias. Madrid: Gestión 2000, 232 pp. ISBN: 9788498750508
}

En La ciencia del caos. El Management y el Marketing en la era de las turbulencias. Philip Kotler, experto en marketing, y John A. Caslione, experto en economía globalizada, describen el comportamiento de las dinámicas socioeconómicas actuales, caracterizadas por la presencia de turbulencias, y cómo las empresas han de adaptarse a ellas. Ambos, que cuentan con un extenso curriculum relacionado con la docencia, investigación y consultoría en proyectos de negocio, proponen el desarrollo e implementación de lo que llaman la ciencia del caos, como la estrategia más eficaz para las organizaciones empresariales de cara a su objetivo fundamental: su supervivencia $y$, en un segundo plano, su crecimiento.

Así, en el primero de sus seis capítulos (recogidos en 197 páginas), los autores hablan de la nueva realidad global y de sus riesgos. Realidad en la que por su alto grado de interconexión e incertidumbre, "un cambio (...) puede extenderse a otros países y crear una turbulencia masiva que lanzaría a todo el sistema hacia resultados inesperados" (p. 19). Es decir que (inspirados en la naturaleza) definen a las turbulencias como "aquellos cambios rápidos e impredecibles que se producen en el entorno externo o interno de una organización que afectan a su rendimiento" (p. 27). Entienden que tales cambios estructuran una economía de nueva realidad con mayores sacudidas y disrupciones debido a una serie de factores tales como, por ejemplo, las TIC y la acentuación de la interconexión e interdependencia que generan, las innovaciones disruptivas que rompen el statu quo tecnológico y la jerarquía en los diferentes mercados, el nuevo protagonismo de los mercados emergentes que entran en lucha directa con los mercados consolidados, o el incremento del poder de clientes e inversores gracias a su acceso a la información y comunicación mediante nuevas plataformas.

Ante estos factores turbulentos, Kotler y Caslione sostienen que las compañías deberán actuar con inteligencia preparándose para las peores situaciones y centrándose en lo que mejor hacen. En ese sentido, "es esencial que las medidas de ahorro de costes no afecten en el cociente de singularidad de la empresa, que no deje de cubrir las necesidades o las expectativas de los clientes ni ponga en peligro su cultura y sus valores. [Por eso ha de contar con la] precisión de un láser para evaluar dónde debe realizar los recortes adecuados" (p.70), y así proteger su corazón productivo e incrementar su valor. Para ello cada organización tendrá que desarrollar su propia estrategia pues deberán atender a sus especificidades, dado que "la turbulencia (...) sitúa a cada empresa en un escenario diferente" (p. 72). En cualquier caso insisten en que el talento y el marketing son dos pilares que toda empresa tendrán que reforzar en situaciones adversas, pues son el motor de la innovación. Con el marketing se asegura el valor de la marca, dado que "la habilidad de seguir innovando constituye una de las pocas maneras de mantener la competitividad y alejarse de la competencia. [Es decir que] la innovación conduce a resultados, crecimiento y valoración" (p. 76); y para ello el talento es imprescindible. Los autores ilustran la importancia de la innovación con el ejemplo de Starbucks Coffe y McDonal's. Los beneficios de la primera marca descendieron un $97 \%$ durante el tercer trimestre de 2008, mientras que los de la segunda crecieron en torno a un $5,4 \%$ en ese mismo periodo, haciéndose con la cuota de mercado que la otra había dejado escapar. McDonal's había creado "una nueva línea de ofertas especiales [combinando] precios más bajos y cantidades más pequeñas, todo ello con técnicas de marca completamente nuevas para generar nuevo valor para el cliente, precisamente en el momento en que este más lo [necesitaba]" (p. 78); incluso reestructuró sus locales para ofrecer espacios nuevos en los que tomar café en la mayor estrategia de diversificación que nunca ha realizado. Por su parte, Starbucks Coffe no aportó nada diferente entre las ofertas de sus productos en momentos de dificultades económicas. Sólo reaccionó con alguna ligera modificación (bocadillos calientes en el desayuno o servicio "sin bajar del coche" en algunos locales). Algo superficial que no añadía valor a la marca, dado que no adaptaba su actividad a las nuevas circunstancias de sus clientes.

En esta dirección, en la obra se insiste que es de vital importancia que la estrategia empresarial se centre en detectar cuanto antes los síntomas que puedan desatar las turbulencias y así aprovechar las oportunidades que esconden (tal y como hizo McDonal's). Para conseguirlo, los autores proponen "desarrollar un sistema de alerta temprana [SAT] efectivo que sea capaz de detectar tantas turbulencias como sea posible, tan rápidamente como sea posible y con tanta antelación como sea posible" (p. 102). Después habría que establecer con mucha claridad los objetivos, tales como "la identificación y reducción de riesgos, incertidumbres y debilidades, así como el reconocimiento y el aprovechamiento de oportunidades" (p. 103). Una parte esencial de esta estrategia es la de construir diferentes escenarios futuros tomando como referente el escenario presente y centrándose en los comportamientos hipotéticos de todos los stakeholders (todos aquellos que influyen en la empresa). Es por ello que Kotler y Caslione creen 
oportuna una visión holística de la estrategia y de sus agentes, atendiendo a la visión de cada uno de éstos para construir escenarios futuros veraces, eliminando tantas incertidumbres como sea posible. Para ello consideran necesario que se delimite el asunto clave de la estrategia, su ámbito y tiempo, además se han de identificar a los stakeholders fundamentales, trazar mapas de las turbulencias, encontrar las incertidumbres clave, definir los escenarios clave (de 2 a 4), evaluarlos y tomar las decisiones más eficaces (adoptando como referente una variable principal sobre la que actuar).

Con esta estrategia se incorporaría la ciencia del caos en la empresa $y$, tal y como ellos afirman, no hacerlo sería erróneo pues "es un signo de debilidad no tomar decisiones basadas en hechos ni cambiar la dirección estratégica cuando las condiciones lo permiten" (p. 106). Además, el principal valor de la construcción de escenarios es que permite "ensayar el futuro" y si éste no se da como se había previsto, se podrá actuar de otra manera en base a los escenarios alternativos planificados, contando siempre con un plan de acción. Algo que, como ellos reflejan, viene haciendo IKEA desde hace años, marca que "por ejemplo, cuando caen las ventas de piezas de mobiliario caras y escogidas en una tienda o en una zona predefinida o en una región, automáticamente (...) aumenta el espacio de exposición de piezas más baratas, y simultáneamente, reduce el espacio de exposición de los productos caros. En caso contrario, cuando las ventas de productos caros aumenta, incrementan también el espacio de exposición" (p. 121).

Según los dos expertos, este sistema de gestión del caos se ha de integrar atendiendo cada empresa a las debilidades de cada departamento estratégico y redistribuyendo su capital en los puntos fuertes para seguir fortaleciéndolos. Por ejemplo, creen que en el departamento financiero se ha de trabajar para alcanzar el crecimiento orgánico de la compañía y garantizar su flexibilidad, aparte de cumplir con los proveedores, reducir gastos innecesarios, externalizar funciones prescindibles y asegurar un capital que garantice un margen de actuación; así afirman que todo ello "puede marcar una notable diferencia al permitir a los directores financieros aprovechar las oportunidades que la siguiente recesión pueda proporcionar" (p. 136). Por su parte, en fabricación y operaciones los autores señalan que los ejecutivos de estas áreas han de "llevar a cabo un riguroso análisis para racionalizar la estructura de costes de la empresa sin hacer recortes en las áreas de alto valor de la operación" (pp. 142-143). Para ello explican que se han de identificar a los mejores trabajadores y a los que son prescindibles, invirtiendo en su formación y haciéndoles partícipes en la toma de decisiones; también apuntan a que se han de buscar las mejores alianzas con terceros para alcanzar los objetivos comunes, estrechando el enfoque del negocio, manteniendo la proposición de valor, invirtiendo en oportunidades y uniendo a todos los stakeholders. Por hablar de un departamento estratégico más, en la obra se recomienda que desde recursos humanos se trabaje para sacar lo mejor de cada empleado siendo honesto con ellos, recompensándolos de manera creativa y animándolos a que participen en las decisiones difíciles de la organización; también se insiste en la importancia de seguir contratando talentos y de motivar a los que ya forman parte de la plantilla.

Como es comprensible, Kotler y Caslioine hacen mención especial a las áreas de marketing y ventas. Afirman que éstas son fundamentales y que se han de adaptar cuanto antes al cambio de actitudes de los clientes (ante una turbulencia) pues "si uno sabe hacia dónde se desplazan (...) deberá estar preparado para ajustar la oferta. [Es decir] no basta con recortar costes. Hay que hacer ajustes en la línea de producto y en el paquete de servicios" (p. 171). Esto permitiría adaptarse a las nuevas necesidades mientras se mantiene la proposición de valor. También es importante prestar atención a los competidores y hacerse fuerte ante sus debilidades para incrementar la cuota de mercado. En cualquier caso, estos expertos proponen los siguientes pasos para las áreas de marketing y ventas: 1) conservar a los clientes más fieles; 2) luchar por los clientes leales de los competidores; 3) estudiar a los clientes en profundidad ante sus cambios con estudios con presupuestos adaptados a la turbulencia; 4) mantener o incrementar el presupuesto en marketing; 5) centrarse en lo seguro $y$ en los valores fundamentales; 6) deshacerse de lo que no funciona (como la publicidad cara) y centrarse en alternativas efectivas (publicidad en soportes más rentables o comunicación on-line); 7) no rebajar el precio, sino sacar nuevas líneas de productos que respondan a las nuevas necesidades de los clientes; y 8) conservar las marcas fuertes y deshacerse de las débiles, luchando por aquellos sectores en los que la presencia sea fuerte a través de, por ejemplo, la publicidad y abandonando los mercados en la que la presencia sea débil.

Las turbulencias, en resumen y según los autores del libro, exigen actuar en tiempos más cortos, adoptar enfoques multifuncionales y descentralizar las grandes organizaciones para dar más autonomía a sus unidades. Sólo así se podrá conseguir la sostenibilidad del negocio de la empresa (SNE), es decir, reconociendo "los factores sociales, económicos, medioambientales y éticos que afectan directamente a la estrategia"; factores (tanto internos como externos), que incrementan su relevancia "dada la ampliación de las expectativas sociales de responsabilidad corporativa." Con esto Kotler y Caslioine proponen una estrategia que "maximice el valor (...) de las empresas a largo plazo (...) sin comprometer nunca el valor a [dicho] plazo. (...) Para ello es fundamental la conservación de activos bien gestionados, la reposición de productos y servicios innovadores y una reputación favorable [para con todos los] stakeholders" (p. 192). Con esta estrategia que proponen, se ha de adoptar un enfoque dual (a corto y a largo plazo), y así definir con claridad la empresa, adaptarla a las nuevas 
necesidades y optimizar sus operaciones $y$, por otro lado (a largo plazo), redefinir la empresa, reformarla y reorganizarla para los retos futuros y para gestionar el cambio.

En este sentido, el objetivo ha de ser crear y defender una buena reputación, que se ha de gestionar muy bien en periodos turbulentos. Valores como la sensibilidad hacia el mundo que les rodea, la conciencia de su identidad o la tolerancia hacia las nuevas ideas, son maneras de hacer empresa que suelen asegurar su supervivencia. Éstos pueden ser principios que marquen la diferencia ante una sociedad que valora cada vez más el lado humano de las organizaciones, tanto que pueden ser ventajas para afianzar alianzas empresariales que lleven a la compañía al éxito. $Y$ es que, tal y como se defiende en toda la publicación, para las empresas "es cada vez más importante ser reales, originales, genuinas, sinceras y auténticas" (p. 211).

Moisés Alonso Baratas Universidad Complutense de Madrid, España moisesalonso20@gmail.com

Recibida: 29-09-2015

Aceptada: 23-10-2015

(c) (1) (3) 